\title{
Synthesis and Characterization of Multi-Pod-Shaped Gold/Silver Nanostructures
}

\author{
Hao Ming Chen, ${ }^{\dagger}$ Chia Fen Hsin, ${ }^{\dagger}$ Ru-Shi Liu,,$\dagger$ Jyh-Fu Lee, ${ }^{\ddagger}$ and Ling-Yun Jang \\ Department of Chemistry, National Taiwan University, Taipei 106, and National Synchrotron Radiation \\ Research Center, Hsinchu 300, Taiwan
}

Received: January 11, 2007; In Final Form: February 17, 2007

\begin{abstract}
We describe here a novel method which shows that related large molecules, tannic acid, can control the morphology of silver/gold nanoparticles, resulting in the formation of multi-pod-shaped nanostructures. In this work, multi-pod-shaped gold/silver nanostructures have been synthesized using tannic acid as a reducing as well as a capping agent. The multi-pod-shaped $\mathrm{Au} / \mathrm{Ag}$ nanostructures have been confirmed by transmission electron microscopy. The growth process of gold/silver nanostructures has been studied by UV/vis spectroscopy and extended X-ray absorption fine structure analysis. On the basis of these results, we propose a model explaining the role of tannic acid in the growth of gold/silver nanostructures. The reducing and capping properties of tannic acid favor the formation of unisotropic crystal growth. The growth of gold/silver nanostructures occurs as a consequence of the galvanic replacement reaction between $\mathrm{Au}^{3+}$ and $\mathrm{Ag}^{0}$ and subsequent reduction of both metal ions by tannic acid. Furthermore, it was found that not only the amount of gold ions but also the galvanic replacement reaction between silver and chloroauric acid plays an important role in the morphology control of the multi-pod-shaped nanostructures.
\end{abstract}

\section{Introduction}

There has been growing interest in biomimetic mineralization approaches for the creation of nanoscale materials with a complex shape and controlled size, shape, and polymorph under ambient conditions in aqueous solutions. ${ }^{1}$ The biomimetic synthesis of inorganic nano- and mesostructures utilizes environmentally benign, "green" conditions in which the crystal morphology and size have often been regulated by biomolecules or the organism. ${ }^{2}$ Some fundamental studies have revealed that biomolecules can selectively recognize inorganic surfaces. ${ }^{3}$ Tannic acid is typically hydrolyzed tannin, a mixed gallotannin composed of gallic acid esters of glucose, which has been used for the biomimetic growth of inorganic nanoparticles. It has antimutagenic, anticancer, and antioxidant properties, reduces serum cholesterol and triglycerides, and suppresses lipogenesis by insulin. ${ }^{4}$ As a result, controlling the size and shape of nanocrystalline materials is a key issue in current nanoscience research. These nanostructures exhibit very interesting electrical, optical, and chemical properties, which cannot be achieved by the corresponding bulk materials. Generally, sphere-shaped inorganic nanoparticles (NPs), both semiconducting and metallic, have been of particular interest to the broad scientific community for decades. Fundamentally, in the case of semiconducting nanoparticles, the light that is absorbed and emitted can be tunable by diameter because the photogenerated electron-hole pair has an exciton diameter that is in the range of $1-10 \mathrm{~nm} .^{5,6}$ For metallic nanoparticles, interesting optical and electronic effects are expected in the range of $\sim 10-100 \mathrm{~nm}$ since the mean free path of an electron in a metal is $10-100 \mathrm{~nm}^{7}$ Recently, the syntheses of metal nonsphericals such as rod, 8,9 wires, ${ }^{10,11}$ prisms, ${ }^{12}$ cubes, ${ }^{13-15}$ and multipods ${ }^{15,16}$ were carried out via wet chemical methods. It was observed that the optical

* To whom correspondence should be addressed. E-mail: rsliu@ ntu.edu.tw.

$\dagger$ National Taiwan University.

$\doteqdot$ National Synchrotron Radiation Research Center. properties of silver and gold nanoparticles are tunable throughout the visible and near-IR regions of the spectrum as a function of the nanoparticle size, shape, and local environment. ${ }^{8}$ On the other hand, there is great potential for synthesizing the nanomaterials that are spheres of defined size and/or specific structure for optical, catalytic, and biological applications. ${ }^{17}$ Added to these, molecules adsorbed to the surface of gold and silver nanoparticles undergo enhanced surface-enhanced Raman scattering effects owing to the coupling of the plasmon band of the irradiated metal with the molecules' electronic states. ${ }^{18}$ Thus, application of metallic nanoparticles as optical sensors has been reported. ${ }^{19}$ In addition, bimetallic nanoparticles have been considered to be valuable for investigating the relationship between performance and their structures. ${ }^{20}$ Taton et al. reported that when single-nanoparticle probes are used in recognizing DNA segments immobilized on a chip, coupled with a signal amplification method based on promoted reduction of silver, the sensitivity exceeds that of the analogous fluorophore system by 2 orders of magnitude. ${ }^{21}$

The study of the extended X-ray absorption fine structure (EXAFS) has been particularly useful in providing structural information about the noncrystalline and the crystalline materials. $^{22,23}$ EXAFS is a short-range probe of structure and gives results for local correlations around the absorbing atom, specifically the nearest neighbor interatomic distances and coordination numbers. Due to the use of monochromatic radiation, EXAFS is element-selective and consequently well suited to samples containing more than one type of metal atom or containing substrate lattices which would interfere with diffraction measurement. The objective of the present investigation is the synthesis of multi-pod-shaped gold/silver and the study of its growth process using EXAFS at room temperature.

Herein, we report the synthesis of multi-pod-shaped gold/ silver nanostructures using tannic acid as a biomolecule and the study of its growth process. The multi-pod-shaped gold/ silver nanostructures have been prepared via the reduction of 
$\mathrm{HAuCl}_{4}$ by tannic acid at boiling temperature. Tannic acid was used as both a reductant and a capping agent. The reduction process of $\mathrm{HAuCl}_{4}$ by tannic acid results in the formation of multi-pod-shaped morphology for gold/silver nanostructures due to unisotropic crystal growth. Furthermore, it was observed that not only the amount of gold ions but also the galvanic replacement reaction between silver and chloroauric acid plays an important role in the morphology control of the $3 \mathrm{D}$ nanostructures. The synthesis of these novel nanostructures and the growth process using characterization techniques will be discussed in this paper.

\section{Experimental Section}

Chemicals and Materials. Hydrogen tetrachloraurate(III) hydrate, trisodium citrate dehydrate $(99 \%)$, silver nitrate $(99 \%)$, and tannic acid $\left(M_{\mathrm{w}}=1701\right)$ were obtained from Acros Organics and used without further purification. The water used throughout this investigation was reagent-grade water, produced using a Milli-Q SP ultrapure water purification system from Nihon Millipore Ltd., Tokyo.

Preparation. In a typical preparation procedure, $50 \mathrm{~mL}$ of $\mathrm{AgNO}_{3}$ aqueous solution $(0.4 \mathrm{mM})$ was prepared and then heated at $95{ }^{\circ} \mathrm{C}$ for $6 \mathrm{~min}$. The reaction mixture was maintained at this temperature under magnetic stirring. Next, $5 \mathrm{~mL}$ of tannic acid $(2 \%)$ was added to the $\mathrm{AgNO}_{3}$ solution. After the solution was stirred for $10 \mathrm{~min}$, silver nanoparticles were formed at this stage. Then the desired volume of $\mathrm{HAuCl}_{4}(25 \mathrm{mM})$ solution as the source of $\mathrm{Au}^{3+}$ was injected into the as-prepared solution of silver nanoparticles, and stirring was continued for $15 \mathrm{~min}$. After the reaction mixture was cooled to room temperature, the product was isolated by centrifugation and washed with water several times. For a hollow structure preparation, the colloidal nanoparticles were prepared by adding $5 \mathrm{~mL}$ of sodium citrate (1\%) to $50 \mathrm{~mL}$ of a silver metal salt $\left(\mathrm{AgNO}_{3}, 0.4 \mathrm{mM}\right)$ solution. The solution was then heated at $95{ }^{\circ} \mathrm{C}$ in an oil bath for 15 min, and then $0.8 \mathrm{~mL}$ of $25 \mathrm{mM} \mathrm{HAuCl} 4$ solution was added dropwise for another $15 \mathrm{~min}$. Stirring was maintained throughout the synthesis. All experimental procedures were performed in an open atmosphere.

Characterization of Nanoparticles. The UV/vis spectra of the colloidal nanoparticle solution were obtained using a Shimadzu UV-1700 spectrophotometer with a $1 \mathrm{~cm}$ quartz cell at room temperature. The surface morphology of the samples was studied by transmission electron microscopy (TEM) (JEM2010, $200 \mathrm{kV}$ ). The specimens were obtained by placing many drops of the colloidal solution onto a Formvar-covered copper grid and evaporating it in air at room temperature. Prior to specimen preparation, the colloidal solution was sonicated for 1 min to improve the dispersion of particles on the copper grid. The samples used in the EXAFS measurement were prepared by concentrating $2000 \mathrm{~mL}$ of the previously obtained colloidal dispersions to $5-10 \mathrm{~mL}$ under nitrogen at a reduced pressure. A series of EXAFS measurements of the synthesized samples were made using synchrotron radiation at room temperature. Measurements were made at the Au $\mathrm{L}_{\mathrm{III}}$ edge $(11918 \mathrm{eV})$ and the $\mathrm{Ag} \mathrm{K}$ edge $(25514 \mathrm{eV})$ with the sample held at room temperature.

EXAFS Data Analysis. The Wiggler-C beam line of the National Synchrotron Radiation Research Center (NSRRC), Taiwan, has been designed for such experiments. The backscattering amplitude and phase shift functions for specific atom pairs were calculated ab initio using the FEFF7 code. X-ray absorption data were analyzed following standard procedures, including preedge and postedge background subtraction, nor-

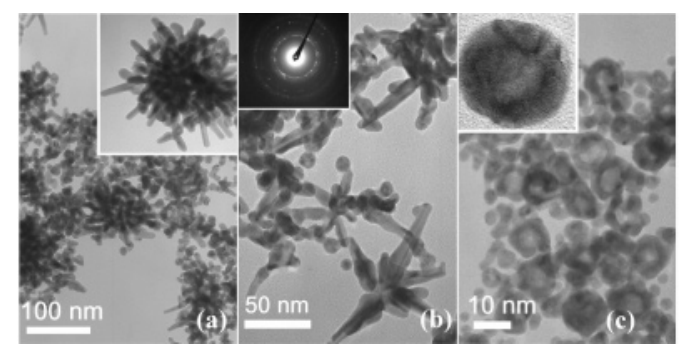

Figure 1. TEM micrographs of the $\mathrm{Au} / \mathrm{Ag}$ nanopolypods under different volumes of $\mathrm{HAuCl}_{4}$ solution: (a) $1.6 \mathrm{~mL}$ and (b) $0.8 \mathrm{~mL}$ of $\mathrm{HAuCl}_{4}$ solution added to the as-prepared silver nanoparticle solution in the presence of tannic acid; (c) $0.8 \mathrm{~mL}$ of $\mathrm{HAuCl}_{4}$ solution added to the as-prepared silver nanoparticle solution in the presence of sodium citrate.

malization with respect to edge height, Fourier transformation, and nonlinear least-squares curve fitting. ${ }^{24}$ The normalized $k^{3}$ weighted EXAFS spectra, $k^{3} x(k)$, were Fourier-transformed in the $k$ range from 2.5 to $14 \AA^{-1}$ to reveal the contribution of each bond pair on the Fourier transform (FT) peak. The experimental Fourier-filtered spectra were obtained by performing an inverse Fourier transformation with a Hanning window function with $r$ between 1.9 and $3.2 \AA$. The $S_{0}{ }^{2}$ (amplitude reduction factor) values of the $\mathrm{Au}$ and $\mathrm{Ag}$ atoms were fixed at 0.8 and 0.83 to determine the structural parameters of each bond pair. Au and Ag edge data were analyzed simultaneously. The Debye-Waller factors, interatomic distances, and coordination numbers of $\mathrm{Au}-\mathrm{Ag}$ and $\mathrm{Ag}-\mathrm{Au}$ bonds were constrained to be equal in both analyses of $\mathrm{Au} \mathrm{L}_{3}$ and $\mathrm{Ag} \mathrm{K}$ edges.

\section{Results}

TEM Analysis of Each Product. TEM was used to image the $\mathrm{Au} / \mathrm{Ag}$ poly-pod-like nanostructures. EM micrographs of the $\mathrm{Au} / \mathrm{Ag}$ nanopolypods after addition of 1.6 and $0.8 \mathrm{~mL}$ of $\mathrm{HAuCl}_{4}$ solution to the as-prepared silver nanoparticles are shown in Figure 1. The selected area electron diffraction pattern, shown as the inset in Figure 1b, indicates that the nanomultipods have a face-centered cubic structure. As a matter of fact, the $\mathrm{Au} / \mathrm{Ag}$ pods significantly increased as more $\mathrm{HAuCl}_{4}$ solution was added. Their mean chemical composition (atom \%), determined by energy-dispersive X-ray microanalysis, is $\mathrm{Au}_{72}$ $\mathrm{Ag}_{28}$, with the surface of the nanopods richer in $\mathrm{Ag}$ (see p S1 of the Supporting Information (SI)). It is apparent that the shell of nanopods is dominated by $\mathrm{Ag}$, while the core is rich in Au. Figure 1c shows $0.8 \mathrm{~mL}$ of $\mathrm{HAuCl}_{4}$ solution was added to the as-prepared silver nanoparticle solution in the presence of sodium citrate. As the $0.8 \mathrm{~mL}$ of $\mathrm{HAuCl}_{4}$ solution reacted with the silver nanoparticles, the galvanic replacement reaction between $\mathrm{Ag}^{0}$ and $\mathrm{Au}^{3+}$ occurred at this stage. ${ }^{22 \mathrm{a}}$ Sodium citrate cannot provide an unisotropic environment for growth of gold, and some hollow structures were fabricated with a shell made of Au/Ag alloy. This suggests that tannic acid acts as a growthinducing agent to form the multi-pod-shaped $\mathrm{Au} / \mathrm{Ag}$ nanostructures and the $\mathrm{Au} / \mathrm{Ag}$ nanopolypods cannot be observed in controlled experiments carried out without tannic acid.

UV/Vis Spectral Analysis of Each Product. Since nanostructures of gold and/or silver are well-known to exhibit distinctive SPR features that depend strongly on their shape, composition, and structure, the galvanic replacement reaction could also be conveniently followed by the UV/vis spectroscopic method. Figure 2 shows the absorption spectra for the mixture of $\mathrm{Au}$ and $\mathrm{Ag}$ nanospheres and after addition of 1.6 and 0.8 $\mathrm{mL}$ of $\mathrm{HAuCl}_{4}$ solution to the as-prepared silver nanoparticle solution in the presence of tannic acid. The surface plasmon 


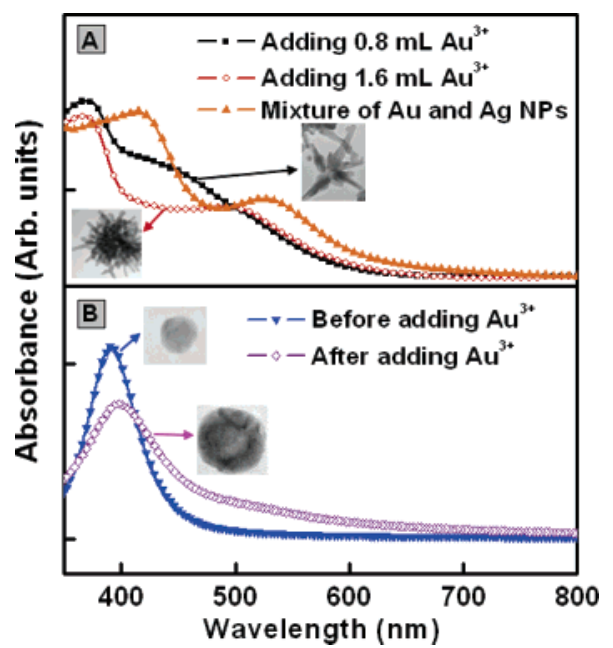

Figure 2. (A) Extinction spectra of a mixture of $\mathrm{Au}$ and $\mathrm{Ag}$ nanospheres. $\mathrm{Au} / \mathrm{Ag}$ nanopolypods after addition of 0.8 and $1.6 \mathrm{~mL}$ of $\mathrm{HAuCl}_{4}$ solution to the as-prepared silver nanoparticle solution. (B) Absorption spectra of the as-prepared $\mathrm{Ag}$ nanoparticles and after addition of $0.8 \mathrm{~mL}$ of $\mathrm{HAuCl}_{4}$ solution to the silver nanoparticle solution in the presence of sodium citrate.

absorption spectra of gold nanorods are usually characterized by two bands. The absorption band appearing at the shorter wavelength is attributed to the transverse band, and that appearing at longer wavelength corresponds to the longitudinal band. ${ }^{25}$ The spectrum of the mixture of gold and silver nanoparticles is also shown in Figure $2 \mathrm{~A}$ to confirm the formation of novel nanostructures. This excludes the possibility of isolated $\mathrm{Au}$ and $\mathrm{Ag}$ nanoparticles or $\mathrm{Au} / \mathrm{Ag}$ alloy nanoparticle formation because the optical absorption spectra of $\mathrm{Au} / \mathrm{Ag}$ alloy nanoparticles show only one plasmon absorption. It was observed that the plasmon band of alloy nanoparticles linearly blue-shifted with increasing silver content, which cannot be explained by a simple linear combination of the dielectric constants of gold and silver content. ${ }^{26}$ It should be noted that the positions of transverse and longitudinal bands were considerably different from those of the usual gold nanorods and/ or $\mathrm{Au}_{\text {core }} \mathrm{Ag}_{\text {shell }}$ nanorods, although the absorption spectra were similarly divided into two parts. ${ }^{27}$ This specific phenomenon can be explained by two important factors: first the deposition of silver on the surfaces of multipods and second subsequent formation of the novel 3D nanostructures. We can compare both for the surface plasmon absorption spectra of gold nanorods and the multipod nanostructures in the present study. ${ }^{25}$ Both transverse and longitudinal plasmon absorption bands of multipod nanostructures shift to the blue with the formation of this novel structure. $\mathrm{Au}_{\text {core }} \mathrm{Ag}_{\text {shell }}$ nanorods had been prepared and studied by Ah and co-workers. ${ }^{27 a}$ Generally, the thickly coated $\mathrm{Au}_{\text {core }} \mathrm{Ag}_{\text {shell }}$ nanorods show the longitudinal surface plasmon absorption at a much shorter wavelength than the thinly coated nanorods and the transverse plasmon absorption at similar wavelengths for both types of core-shell nanorods. It is meaningful to say that the multipod nanoparticles also show the transverse plasmon absorption at a position similar to that observed for $\mathrm{Au}_{\text {core }} \mathrm{Ag}_{\text {shell }}$ nanorods, while the position of the longitudinal plasmon absorption is strongly dependent on the coating of silver and aspect ratio of nanorods. In the present study, the longitudinal plasmon absorption of multipod nanoparticles prepared by using $0.8 \mathrm{~mL}$ of $\mathrm{HAuCl}_{4}$ solution significantly shifted to the blue region, suggesting more silver deposition on the gold surfaces. The plasmon absorption of silver and silver-coated nanorods is also characterized by a sharp peak absorption. Theoretical calculation shows that the sharper longitudinal absorption of silver nanorods has a stronger peak absorption, compared with that of gold nanorods having the same aspect ratio. This signifies that silver and silver-coated nanorods have good optical properties useful for applications. ${ }^{27 a}$ The aspect ratio of nanopods prepared by using $1.6 \mathrm{~mL}$ of $\mathrm{HAuCl}_{4}$ solution was larger than that of nanopods prepared by using $0.8 \mathrm{~mL}$ of $\mathrm{HAuCl}_{4}$ solution, which results in a red shift of the longitudinal plasmon absorption. Besides the effect of silver coating upon surfaces of nanopods, another important factor is electromagnetic interactions of paired particles, which should be taken into account. Because of the reduced symmetry of nanoparticles, electromagnetic interactions of paired particles should depend not only on the mutual separation distance, but also on the mutual orientation. ${ }^{28}$ The spectra of end-to-end interactions are a red shift of the longitudinal rod mode. Conversely, side-to-side interactions of nanorods lead to a blue shift in the main plasmon resonance band with a corresponding growth in the short-axis band. The comparison of the plasmon absorption of multipod nanostructures to the spectra of $\mathrm{Au}_{\text {core }^{-}}$ $\mathrm{Ag}_{\text {shell }}$ nanorods in the literature ${ }^{27}$ shows a slight blue shift of both transverse and longitudinal absorption bands for multipod nanostructures. The observed blue shift is attributable to the side-to-side interactions among nanopods. The longitudinal plasmon band of multi-pod-shaped nanoparticles was dominated by the side-to-side interaction among nanopods (as shown on $\mathrm{p}$ S2 of the SI) and has a lower intensity than that of general gold nanorods. This dampening of the longitudinal absorption bands may have been caused by an interaction between cylindrical and spherical nanoparticles. ${ }^{28}$ Besides the effect of silver deposition and mutual orientation on the spectra, the full width at half-maximum (fwhm) of the absorption bands increases with an increase in the dimensions of the multipods since the change in the electron density becomes slower and slower. ${ }^{29}$ As shown in Figure 2A, after silver nanoparticles reacted with $1.6 \mathrm{~mL}$ of $\mathrm{HAuCl}_{4}$ solution, the longitudinal absorption band of 3D nanopolypods was distributed over a wider range as a result of an increase in the dimensions of the nanopolypods.

Figure 2B shows absorption spectra of the as-prepared $\mathrm{Ag}$ nanoparticles and after addition of $0.8 \mathrm{~mL}$ of $\mathrm{HAuCl}_{4}$ solution to these silver nanoparticles in the presence of sodium citrate. It was observed that the intensity of the $398 \mathrm{~nm} \mathrm{Ag}$ plasmon peak slightly decreased after addition of $0.8 \mathrm{~mL}$ of $25 \mathrm{mM}$ $\mathrm{HAuCl}_{4}$ solution. The reduction in the intensity can be attributed to the partial oxidation of silver nanoparticles even though only a simple electroless plating process was employed. Similar morphological and spectral studies demonstrated that the $\mathrm{Ag}$ nanoparticles were oxidized by $\mathrm{HAuCl}_{4}$ solution to form $\mathrm{Au} /$ $\mathrm{Ag}$ alloy nanoshells as $\mathrm{HAuCl}_{4}$ solution was added. ${ }^{22 a, 30}$

EXAFS Analysis. Figure 3 displays $\mathrm{Au} \mathrm{L}_{3}$ edge EXAFS oscillations of $\mathrm{Au}$ foil and multipod $\mathrm{Au} / \mathrm{Ag}$ nanoparticles (after addition of $0.8 \mathrm{~mL}$ of $\mathrm{HAuCl}_{4}$ ). An interesting change in the oscillatory feature above $\sim k=5.5 \AA^{-1}$ was observed for $\mathrm{Au}$ coated with the silver shell. This change in the oscillatory feature can be attributed to the presence of Ag near neighbors around $\mathrm{Au}$ atoms, in which $\mathrm{Au}$ and $\mathrm{Ag}$ have substantially varying phase shifts and amplitudes in the backscattering function with $k$. The arrow in the figure indicates oscillation caused by the presence of $\mathrm{Ag}$ for multipod nanoparticles, suggesting that the spectral oscillation changed markedly with the deposition of silver atoms. This large difference facilitates the coordination analysis of the $\mathrm{Au} / \mathrm{Ag}$ system. Figure 4a presents the magnitude of the Fourier transform of $\mathrm{Au} \mathrm{L}_{3}$ edge $k^{3} \chi(k)$, where $k=3.0-14 \AA^{-1}$ of multipod $\mathrm{Au} / \mathrm{Ag}$ nanoparticles. Evidently, a phase shift in $\chi(k)$ is seen, and $\mathrm{Au} / \mathrm{Ag}$ in the first shell appears as a doublet in the 


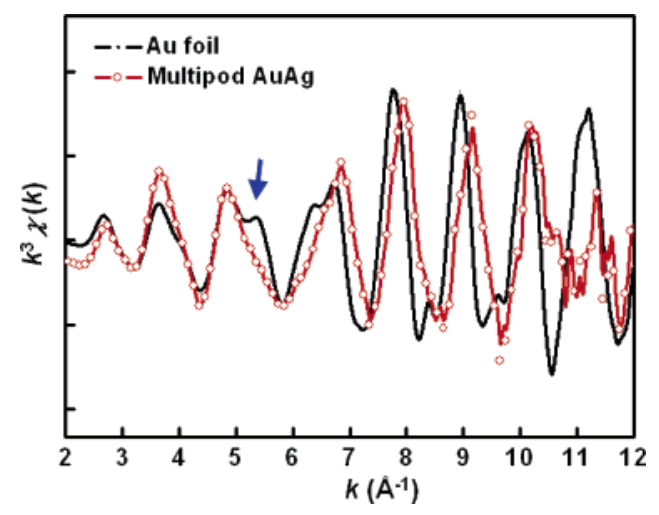

Figure 3. $\mathrm{Au} \mathrm{L}_{3}$ edge EXAFS oscillations for $\mathrm{Au}$ foil and multipod $\mathrm{Au} / \mathrm{Ag}$ nanoparticles $\left(0.8 \mathrm{~mL}\right.$ of $\mathrm{HAuCl}_{4}$ was added). The arrow indicates oscillation caused by the presence of $\mathrm{Ag}$.

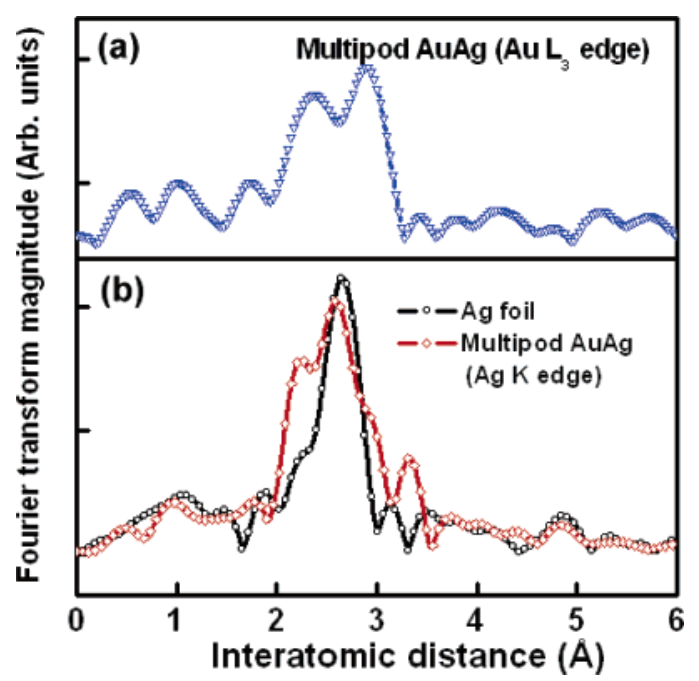

Figure 4. (a) Fourier transforms of the $\mathrm{Au} \mathrm{L}_{3}$ edge $k^{3} \chi(k)$ EXAFS spectrum of multipod $\mathrm{Au} / \mathrm{Ag}$ nanoparticles. (b) Fourier transforms of the $\mathrm{Ag} \mathrm{K}$ edge $k^{3} \chi(k)$ spectrum of $\mathrm{Ag}$ foil and multipod $\mathrm{Au} / \mathrm{Ag}$ nanoparticles.

Fourier transform of $\chi(k)$. The peak intensity at a lower distance exceeds than that at a higher distance because the interference between silver and gold oscillations varies as $\mathrm{Ag}$ is deposited. Notably, both peaks come from the first neighbor with a single distance, and they appear to be closer to the actual bond length because of the backscattering phase shift. The doublet component, however, varies with the amount of deposited Ag because of the difference between both the phase shifts and the backscattering functions of $\mathrm{Au}$ and $\mathrm{Ag}$. This suggests that a significant amount of $\mathrm{Ag}$ is present in the nearest-neighbor shell around Au atoms. Thus, EXAFS analysis of multipod nanoparticles is characteristic of a two-component structure. Moreover, the X-ray absorption spectrum of the Ag K edge was obtained to provide further evidence of the presence of $\mathrm{Ag}$ atoms in multipod nanostructures (Figure 4b). As shown in Figure 4b, the FT-EXAFS spectrum of the Ag K edge of the multipod nanoparticles exhibits a distinct interference at the bimetallic interface in comparison with that of the Ag foil. The FT-EXAFS spectrum was employed to derive the structural parameters on the basis of a two-shell model that involves $\mathrm{Au}-\mathrm{Au}, \mathrm{Au}-\mathrm{Ag}$, $\mathrm{Ag}-\mathrm{Ag}$, and $\mathrm{Ag}-\mathrm{Au}$ shells to characterize the near-range structure near $\mathrm{Au}$ and $\mathrm{Ag}$ atoms, as presented in Table 1. Detailed curve-fitting analyses of EXAFS results give valuable information about the coexistence of $\mathrm{Au}-\mathrm{Au}$ and $\mathrm{Au}-\mathrm{Ag}$ bonds in the multipod nanoparticles. Au/Ag bimetallic nanoparticles, as described above, can be fabricated by this method. In the
TABLE 1: EXAFS Structural Parameters of Multipod Nanoparticles

\begin{tabular}{cccccr}
\hline sample & path & $\mathrm{CN}$ & $R(\AA)$ & $\sigma^{2}\left(\AA^{2}\right)$ & $\Delta E(\mathrm{eV})$ \\
\hline multipod NPs $\left(\mathrm{Au} \mathrm{L} \mathrm{L}_{3}\right)$ & $\mathrm{Au}-\mathrm{Au}$ & $9.8(7)$ & $2.86(4)$ & $0.0088(8)$ & $-3.3(7)$ \\
& $\mathrm{Au}-\mathrm{Ag}$ & $2.0(5)$ & $2.87(5)$ & $0.0108(9)$ & $4.2(6)$ \\
Multipod NPs $(\mathrm{Ag} \mathrm{K})$ & $\mathrm{Ag}-\mathrm{Ag}$ & $5.9(7)$ & $2.87(5)$ & $0.0103(8)$ & $3.2(5)$ \\
& $\mathrm{Ag}-\mathrm{Au}$ & $5.8(6)$ & $2.85(6)$ & $0.0101(9)$ & $-4.0(4)$
\end{tabular}

same matter, a similar result was drawn from the structural refinement of the $\mathrm{Ag} \mathrm{K}$ edge. EXAFS refinement results show the crystalline nature of the Au/Ag alloy, whereas the Ag shell was found to be not single crystalline. It must be noted that the coordination number of multipod nanoparticles was slightly smaller than 12 and the Debye-Waller factor significantly exceeded that of gold foil (0.0062), indicating some structural disorder in the nanoparticles. These results demonstrate the nature of the nanopolypod materials. Comparing the coordination numbers around each absorbing atom with those calculated from the corresponding model structure, one could elucidate the distribution of the atoms inside the particles. ${ }^{22 \mathrm{a}, 23 \mathrm{~d}, \mathrm{e}, 31}$ Most interestingly, the coordination number of the $\mathrm{Au}-\mathrm{Ag}$ path drawn from the $\mathrm{Au} \mathrm{L}_{3}$ edge was significantly different from that of the $\mathrm{Ag}-\mathrm{Au}$ path drawn from the $\mathrm{Ag} \mathrm{K}$ edge, which implied that $\mathrm{Au}$ and $\mathrm{Ag}$ atoms inside a particle were not in a random alloy structure in which each component was mixed with the others. However, the $\mathrm{Au} / \mathrm{Ag}$ bimetallic nanostructure was not a perfect core-shell structure in which the Au metal component was preferentially situated inside the particle and Ag metal was located in the surface region, although some alloying may have occurred via an interdiffusion process between $\mathrm{Ag}$ and $\mathrm{Au}$ atoms. Alloying can, in principle, be caused by an increase in the diffusion coefficient of the metals, which in turn is related to the decline in the melting point of the particles as their size falls in the nanometer region. ${ }^{32}$ Size-dependent spontaneous alloying of silver-coated gold nanoparticles and Au migration from the core to the shell of the particles have been examined. ${ }^{22 b}$ Because the diffusion coefficient of Au nanoparticles is higher than that of the bulk, the density of defects at the bimetallic interface is relatively high. That is, both alloying and galvanic replacement reaction between $\mathrm{Au}^{3+}$ and $\mathrm{Ag}^{0}$ lead to a shell made of $\mathrm{Au} / \mathrm{Ag}$ alloy (Ag-rich). Although EXAFS analysis could not directly verify the formation of core-shell structures, it yielded useful structural information regarding $\mathrm{Au}$ and $\mathrm{Ag}$ atoms.

\section{Discussion}

We must emphasize the fact that presence of both silver and tannic acid plays an important role in the formation of multipod-shaped $\mathrm{Au} / \mathrm{Ag}$ nanostructures. When $\mathrm{Au}^{3+}$ ions are introduced into the $\mathrm{Ag}$ nanoparticle solution, two critical reactions have to be considered simultaneously: first the galvanic replacement reaction between $\mathrm{Au}^{3+}$ and $\mathrm{Ag}^{0}$ and second the reduction of both metal ions by tannic acid involved in the growth of $\mathrm{Au} / \mathrm{Ag}$ nanopods. The galvanic replacement reaction between $\mathrm{Ag}^{0}$ and $\mathrm{Au}^{3+}$ has been discussed in detail. ${ }^{22 \mathrm{a}, 30}$ In a typical displacement reaction, after addition of $\mathrm{Au}^{3+}$ ions to the $\mathrm{Ag}$ nanoparticle solution, $\mathrm{Ag}^{0}$ atoms were oxidized to $\mathrm{Ag}^{+}$ by $\mathrm{Au}^{3+}$ ions. After galvanic replacement reaction occurred, $\mathrm{Au}^{0}$ atoms and $\mathrm{Ag}^{+}$were formed. Moreover, the role of tannic acid as a reducing agent is very significant for the galvanic displacement, which results in formation of both $\mathrm{Au}^{0}$ and $\mathrm{Ag}^{0}$ atoms. However, the reduction of $\mathrm{Au}^{3+}$ ions is thermodynamically more favorable as compared with that of $\mathrm{Ag}^{+}$ions; hence, the formation of $\mathrm{Au}^{0}$ atoms is more favored. ${ }^{33} \mathrm{Ag}^{+}$ions were then reduced to $\mathrm{Ag}^{0}$ by tannic acid in a later stage after all $\mathrm{Au}^{3+}$ 
(a)
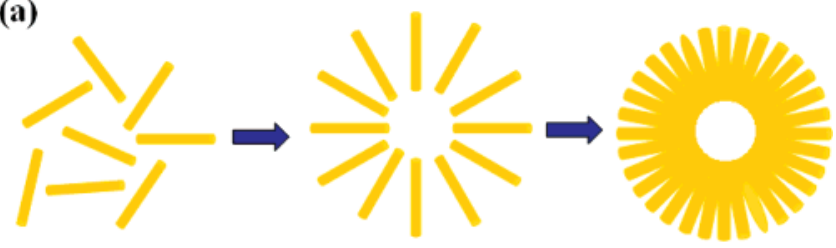

(b)

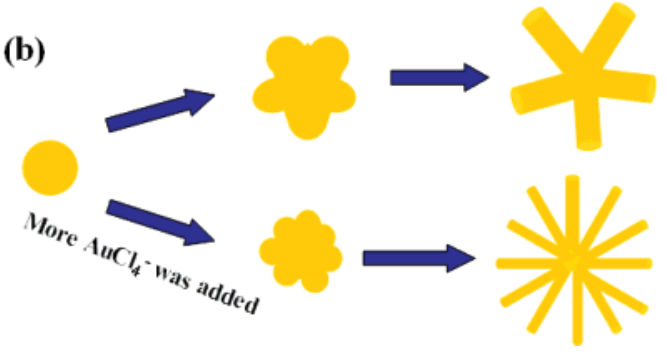

Figure 5. Growth mechanism: (a) assembly from numerous nanorods; (b) growth via a seed-mediated process.

ions in the solution were drained off. Therefore, the composition of the core part of the nanopods was richer in $\mathrm{Au}$, and the shell part was richer in Ag. Tannic acid may also play a role in crystal growth similar to that of other polymers such as poly(vinylpyrrolidone) and polyacrylate, ${ }^{13}$ which block the facet of metal to induce an unisotropic growth. On the other hand, as demonstrated in the previous studies, the presence of silver would give rise to the unisotropic growth of gold..$^{8-10,15,34}$ To confirm the role of silver in unisotropic growth, the reduction of gold in the presence of tannic acid was carried out. The controlled experiment shows that gold and silver nanparticles were prepared by using tannic acid as a reductant (as shown on p S3 of the SI). The resulting products of both gold and silver were spherical, and no kind of unisotropic growth could be observed. This suggests the role of silver involved in unisotropic growth of gold. The recent report about silver underpotential deposition on growing gold nanoparticles provides the role of silver and a possible rationale for the excess ions in solution. ${ }^{35 a}$ Silver underpotential deposition is the reduction of $\mathrm{Ag}^{+}$at a metal substrate. A greater positive shift in potential for silver underpotential deposition on gold surfaces is observed on $\{110\}$ surfaces compared to the $\{100\}$ or $\{111\}$ faces. Fast silver deposition inhibits gold growth on the sides and results in preferential growth of gold at the ends. Further shape control can be achieved by introducing foreign silver ions during the gold nanocrystal growth process. ${ }^{36}$ Considering the above results, we can suggest that gold/silver unisotropic growth chiefly concerned the presence of both silver and tannic acid in the present system.

Furthermore, the kinetics of nucleation is too difficult to study, whereas the subsequent growth stage can be more readily examined. According to the above observation, we propose two different models for the growth mechanism of the multipod Au/ Ag nanostructures (Figure 5). In model a, the Au/Ag nanomultipods were derived from the assembly of nanorods. Numerous metal nanorods are formed in an early stage, and the lateral engagement of these building units (nanorods) would naturally lead to the shell structure depicted in Figure 5a. Since the formation of such a shell structure is not observed, the formation of multi-pod-shaped nanostructure must grow via seed-mediated growth. ${ }^{37}$ In model b, polycrystalline nanospheres were formed in an early stage. When the metal ions are introduced into the reaction system, they are reduced to atoms and grow on the surface of spheres formed at an early stage. An epitaxial orientation relationship between the core and shell is favorable, but epitaxial growth is determined by their crystal structures.



Figure 6. Schematic illustration summarizing all reaction and structural changes involved in the galvanic replacement reaction: (a) prepared in the presence of tannic acid; (b) prepared in the presence of sodium citrate.

In the present system, silver and gold cause the silver atoms to preferentially nucleate and grow on the surfaces of gold nanoparticles, rather than homogeneously nucleating and growing from silver nuclei because of the similarities between both the atomic radii and lattice parameters. Although galvanic replacement reaction may have occurred at this stage, the reduction of metal ions dominates this reaction because of the strong reduction ability of tannic acid. After the initial growth of seeds on the surfaces of nanospheres, these seeds provide active sites to grow the nanopods. When many $\mathrm{AuCl}_{4}{ }^{-}$ions are employed, a high concentration of metal ions is available for reduction, which results in a faster crystal growth rate. As a consequence of the faster growth rate, crystals grow much less selective in direction and hence produce many seed sites on the surfaces. Finally, more metal nanopods would grow on the surface of the nanosphere than in the case of a few $\mathrm{AuCl}_{4}{ }^{-}$ ions. This model accounts well for the $3 \mathrm{D}$ growth observed in Figure 1.

Figure 6 summarizes all major steps involved in the galvanic replacement process and simultaneous reduction of metal ions by tannic acid and sodium citrate. In the case of tannic acid (path a), after $\mathrm{HAuCl}_{4}$ solution has been added to the dispersion of silver nanospheres, tannic acid will start reducing gold ions in the solution. This results in the generation of seed sites on the surfaces of silver nanospheres to provide active sites for subsequent growth. The first step would be the galvanic replacement process occurring at the interface of $\mathrm{Ag}^{0} / \mathrm{Au}^{3+}$. The released electrons in this process can easily migrate to the surface of the nanoparticle and reduce $\mathrm{AuCl}_{4}{ }^{-}$into $\mathrm{Au}$ atoms. The epitaxial deposition will lead to the formation of a crystal site on the surface owing to a good matching of crystalline structures and lattice constants between gold and silver. During this deposition, $\mathrm{Ag}^{+}$ions continuously diffuse out and dissolve in solution, which results in the formation of a gold-rich core due to dissolution of the silver core. In the second step, the dissolved silver ions are re-reduced to silver atoms by tannic acid, which will then migrate to the nanopod surface. As a result of which, $\mathrm{Au} / \mathrm{Ag}$ alloy is formed on the surface of the nanopods. 
The generated gold and silver atoms continue to grow on the surface of the nanopods and gradually emanate to form the multi-pod-shaped gold/silver nanostructure. As a matter of fact, $\mathrm{Ag}^{+}$ions will not precipitate as $\mathrm{AgCl}$ with $\mathrm{Cl}^{-}$ions because the product of $\left[\mathrm{Ag}^{+}\right]$and $\left[\mathrm{Cl}^{-}\right]$was smaller than the solubility product of $\mathrm{AgCl} .{ }^{30 \mathrm{~d}}$ The silver chloride formed in this manner will be completely soluble in water under the present experimental conditions. In the presence of sodium citrate (path b), when the $\mathrm{HAuCl}_{4}$ solution has been introduced into the dispersion of silver nanoparticles, the replacement reaction will start from the sites having a relatively high surface energy. ${ }^{25 a}$ This reaction is like a corrosion process, with silver being oxidized. The gold generated in this reaction tends to be deposited on the surface of each particle owing to the good matching between gold and silver. In fact, silver and gold tend to form a nearly ideal solid solution because the homogeneous $\mathrm{Au} / \mathrm{Ag}$ alloy will be more stable than either pure Au or pure Ag. ${ }^{38}$ As a result, a hollow structure with a shell made of $\mathrm{Au} /$ Ag alloy is formed in this stage. The extension of this method would be viable to the other kinds of metal materials and is currently under study.

\section{Conclusion}

Tannic acid-based one-pot synthesis of multi-pod-shaped gold/silver nanostructures has been described. We have shown that the amount of gold ions as well as the galvanic replacement between silver and chloroauric acid plays an important role in the morphology control of the multi-pod-shaped nanostructures. It was found that the tannic acid acts as a reducing as well as a capping agent in the synthesis of multi-pod-shaped nanostructures. Moreover, tannic acid favors the formation of unisotropic crystal growth. This methodology is expected to bring about new opportunities for the synthesis of new unisotropic metal nanostructures. This new nanostructure of the metal is expected to find use in a range of applications, especially in biology.

Acknowledgment. We thank the National Science Council of the Republic of China, Taiwan, for financially supporting this research under Contract No. NSC 95-2113-M-002-009.

Supporting Information Available: Elemental analysis of a multipod nanostructure performed on an EDS instrument ( $p$ $\mathrm{S} 1$ ), scheme of the side-to-side and the end-to-end interactions among nanopods (p S3), TEM images of the isolated gold and silver nanparticles prepared by reduction of tannic acid (p S3), and best fitted EXAFS $\mathrm{Au} \mathrm{L}_{3}$ edge spectrum of a multipod nanostructure (p S4) and Ag K edge spectrum of a multipod nanostructure (p S5). This material is available free of charge via the Internet at http://pubs.acs.org.

\section{References and Notes}

(1) (a) Bauerlein, E. Angew. Chem., Int. Ed. 2003, 42, 614. (b) Raveendran, P.; Fu, J.; Wallen, S. L. J. Am. Chem. Soc. 2003, 125, 13940.

(2) (a) Allen, M.; Willites, D.; Mosolf, J.; Young, M.; Douglas, T. Adv. Mater. 2002, 14, 1562. (b) Douglas, T.; Young, M. Adv. Mater. 1999, 11,679 .

(3) (a) Cha, J. N.; Stucky, G. D.; Morse, D. E.; Deming, T. J. Nature 2000, 403, 289. (b) Lee, S. W.; Mao, C. B.; Flynn, C. E.; Belcher, A. M. Science 2002, 296, 892.

(4) Nakamura, Y.; Tsuji, S.; Tonogai, Y. J. Agric. Food Chem. 2003, 51,331 .

(5) Peng, X.; Manna, L.; Yang, W.; Wickham, J.; Scher, E.; Kadavanich, A.; Alivisatos, A. P. Nature 2000, 404, 59.

(6) (a) Manna, L.; Scher, E. C.; Alivisatos, A. P. J. Am. Chem. Soc. 2000, 122, 12700. (b) Lee, S.-M.; Jun, Y.-W.; Cho, S.-N.; Cheon, J. J. Am.
Chem. Soc. 2002, 124, 11244.

(7) El-Sayed, M. A. Acc. Chem. Res. 2001, 34, 257.

(8) Murphy, C. J.; Sau, T. K.; Gole, A. M.; Orendorff, C. J.; Gao, J.; Gou, L.; Hunyadi, S. E.; Li, T. J. Phys. Chem. B 2005, 109, 13857. 1389.

(9) Jana, N. R.; Gearheart, L.; Murphy, C. J. Adv. Mater. 2001, 13,

(10) Chen, H. M.; Peng, H.-C.; Liu, R. S.; Asakura, K.; Lee, C.-L.; Lee, J.-F.; Hu, S. F. J. Phys. Chem. B 2005, 109, 19553.

(11) Jana, N. R. Small 2005, 1, 875.

(12) Jin, R.; Gao, Y.; Mirkin, C. A.; Kelly, K. L.; Schatz, G. C.; Zheng, J. G. Science 2001, 294, 1901.

(13) (a)Sun, Y.; Xia, Y. Science 2002, 298, 2176. (b) Ahmadi, T. S.; Wang, Z. L.; Green, T. C.; Henglein, A.; El-Sayed, M. A. Science 1996, 272,1924

(14) Chen, H. M.; Liu, R.-S.; Li, H.; Zeng, H. C. Angew. Chem., Int. Ed. 2006, 45, 2713.

(15) Sau, T. K.; Murphy, C. J. J. Am. Chem. Soc. 2004, 126, 8648.

(16) (a)Yamamoto, M.; Kashiwagi, Y.; Sakata, T.; Mori, H.; Nakamoto, M. Chem. Mater. 2005, 17, 5391. (b) Chen, S.; Wang, Z. L.; Ballato, J.; Foulger, S. H.; Carroll, D. L. J. Am. Chem. Soc. 2003, 125, 16186. (c) Zhou, Y.; Wang, C. Y.; Zhu, Y. R.; Chen, Z. Y. Chem. Mater. 1999, 11, 2310 .

(17) (a) Zhou, S.; Mcllwrath, K.; Jackson, G.; Eichhorn, B. J. Am. Chem. Soc. 2003, 125, 16186. (b) Bruchez, M.; Moronne, M.; Gin, P.; Weiss, S.; Alivisatos, A. P. Science 1998, 281, 2013.

(18) Kneipp, K.; Kneipp, H.; Itzkan, I.; Dasari, R. R.; Feld, M. S. Chem. Rev. 1999, 99, 2957.

(19) (a) Nie, S.; Emory, S. R. Science 1997, 275, 1102. (b) Mirkin, C A.; Letsinger, R. L.; Mucic, R. C.; Storhoff, J. J. Nature 1996, 382, 607.

(20) Zhou, S.; Mcllwarth, K.; Jackson, G.; Eichhorn, B. J. Am. Chem. Soc. 2006, 128, 1780 .

(21) Taton, T. A.; Mirkin, C. A.; Letsinger, R. L. Science 2000, 289, 1757.

(22) (a) Chen, H. M.; Liu, R.-S.; Asakura, K.; Lee, J.-F.; Jang, L.-Y.; Hu, S.-F. J. Phys. Chem. B 2006, 110, 19162. (b) Shibata, T.; Bunker, B. A.; Zhang, Z.; Meisel, D.; Vardeman, C. F.; Gezelter, J. D. J. Am. Chem. Soc. 2002, 124, 11989. (c) Chen, H. M.; Liu, R.-S.; Jang, L.-Y.; Lee, J.-F.; Hu, S.-F. Chem. Phys. Lett. 2006, 421, 118.

(23) (a) Park, J.; Kim, M. G.; Jun, Y.-W.; Lee, J. S.; Lee, W.-R.; Cheon, J. J. Am. Chem. Soc. 2004, 126, 9072. (b) Chen, H. M.; Peng, H.-C.; Liu, R.-S.; Hu, S.-F.; Jang, L.-Y. Chem. Phys. Lett. 2006, 420, 484. (c) Lu, P.; Teranishi, T.; Asakura, K.; Miyake, M.; Toshima, N. J. Phys. Chem. B 1999, 103, 9673. (d) Molenbroek, A. M.; Haukka, S.; Clausen, B. S. J. Phys. Chem. B 1998, 102, 10680. (e) Bian, C.-R.; Suzuki, S.; Asakura, K.; Lu, P.; Toshima, N. J. Phys. Chem. B 2002, 106, 8587.

(24) Iwasawa, Y. X-ray Absorption Fine Structure for Catalysts and Surfaces; World Scientific: Singapore, 1996.

(25) Kelly, K. L.; Coronado, E.; Zhao, L. L.; Schatz, G. C. J. Phys. Chem B 2003, 107, 668 .

(26) Link, S.; Wang, Z. L.; El-Sayed, M. A. J. Phys. Chem. B 1999 , $103,3529$.

(27) (a) Ah, C. S.; Hong, S. D.; Jang, D.-J. J. Phys. Chem. B 2001, 105, 7871. (b) Liu, M.; Guyot-Sionnest, P. J. Phys. Chem. B 2004, 108 , 5882 .

(28) Gluodenis, M.; Foss, C. A. J. Phys. Chem. B 2002, 106, 9484.

(29) Zhu, J. Phys. Lett. A 2005, 339, 466.

(30) (a) Sun, Y.; Xia, Y. J. Am. Chem. Soc. 2004, 126, 3892. (b) Sun, Y.; Wiley, B.; Li, Z.-Y.; Xia, Y. J. Am. Chem. Soc. 2004, 126, 9399. (c) Sun, Y.; Xia, Y. Nano Lett. 2003, 3, 1569. (d) Sun, Y.; Mayers, B. T.; Xia, Y. Nano. Lett. 2002, 2, 481.

(31) (a) Toshima, N.; Harada, M.; Yamazaki, Y.; Asakura, K. J. Phys Chem. 1992, 96, 9927. (b) Harada, M.; Asakura, K.; Toshima, N. J. Phys. Chem. 1993, 97, 5103. (c) Toshima, N.; Harada, M.; Yonezawa, T.; Kushihashi, K.; Asakura, K. J. Phys. Chem. 1991, 95, 7448.

(32) Buffat, P.; Borel, J.-P. Phys. Rev. A 1976, 13, 2287.

(33) Lide, D. R. CRC Handbook of Chemistry and Physics, 74th ed.; CRC Press: Boca Raton, FL, 1997.

(34) Pileni, M. P. Nat. Mater. 2003, 2, 145.

(35) (a)Liu, M.; Guyot-Sionnest, P. J. Phys. Chem. B 2005, 109, 22192. (b) Orendorff, C. J.; Murphy, C. J. J. Phys. Chem. B 2006, 110, 3990. (c) Kim, F.; Song, J. H.; Yang, P. J. Am. Chem. Soc. 2002, 124, 14316.

(36) Kim, F.; Connor, S.; Song, H.; Kuykendall, T.; Yang, P. Angew. Chem., Int. Ed. 2004, 43, 3673.

(37) (a) Gole, A.; Murphy, C. J. Chem. Mater. 2004, 16, 3633. (b) Sun, Y.; Yin, Y.; Mayers, B. T.; Herricks, T.; Xia, Y. Chem. Mater. 2002, 14, 4736.

(38) Shi, H.; Zhang, L.; Cai, W. J. Appl. Phys. 2000, 87, 1572. 